MUZIKOLOŠKI ZBORNIK - MUSICOLOGICAL ANNUAL IV, LJUBLJANA 1968

\title{
SEZONA 1826/27 V STANOVSKEM GLEDALIŠČU V LJUBLANI
}

\author{
Jože Sive c (Ljubljana)
}

Obdobje zadnjih let 18. in začetka 19. stoletja je nemirno obdobje Napoleonovih vojn. Avstrija je v dolgotrajnih vojnah s Francijo utrpela težke izgube in inflacija je povzročila obubožanje najširših krogov prebivalstva. ${ }^{1}$ Moč stanov je pešala že vse od druge polovice 18. stoletja.

Že vrsto let izza francoske okupacije je bila uprava ljubljanskega Stanovskega gledališča prisiljena jemati posojila iz provincialnega fonda za popravila gledališkega poslopja, pa tudi za dodeljevanje podpore impresarijem. Razen tega je vedno bolj izostajalo plačevanje davkov, ki jih gledališka direkcija ni mogla poravnati že od leta 1814 dalje. ${ }^{2} \mathrm{~V}$ svojem težkem položaju se je obračala na lastnike lož in prijatelje gledališča za prostovoljne prispevke, ki pa niso bili stalni in zadostni.

Ker se je gubernij prepričal, da vladajo $\mathrm{v}$ gledališču in njemu pripadajočem fondu tako slabe razmere, da mora gledališče prenehati delovati, če se ne ustvari nov red, je leta 1819 izdal odlok o reorganizaciji gledališke uprave, ki so jo poslej sestavljali gubernijski svetnik in šest odbornikov: po dva predstavnika plemstva in uglednega meščanstva ter direktor in en član Filharmonične družbe. Gubernij je zahteval v gledališki upravi zastopstvo filharmonije, ker je bila potrebna gledališkemu orkestru pomoč in vodstvo, kar je bilo pričakovati prav od te ustanove. ${ }^{3}$ $\mathrm{S}$ tem, da je postal direktor uprave gubernijski svetnik, ki je bil tedaj grof Leopold Stubenberg, pa je hotel gubernij uveljaviti svoje nadzorstvo nad gledališčm in njegovo programsko politiko, ki je bila $v$ času poostrene cenzure predmarčne Avstrije občutljiv problem. ${ }^{4}$

Vendar se delo Stanovskega gledališča po omenjeni reorganizaciji ni prav nič spremenilo, kajti ta ni imela bistvenega vpliva niti na repertoar niti na ekonomsko stanje gledališča, ki se ni prav nič izboljšalo, ampak

1 Prim. Hellbling E., Oesterreichische Verfassungs- und Verwaltungsgeschichte, Wien 1956, str. $332-339$.

2 Prim. DAS-Gl a, (Državni arhiv Slovenije - gledališki akti), Fasc. 75, 1820 , št. 55; Fasc. 78, 1827, št. 4 .

3 Prim. DAS-Gl a, Fasc. 74, 7. V. 1819; Stenographischer Bericht der XX. Sitzung des krainischen Landtages zu Laibach vom 3. März 1863.

4 Cvetko D., Zgodovina glasbene umetnosti na Slovenskem, II, Ljubljana 1959, str. 211; Grafenauer B., Zgodovina slovenskega naroda, V, Ljubljana 1962; str. 188 do 195. 
le še slabšalo. Reorganizacija je bila izključno formalnega značaja in nastala je predvsem zaradi smernic, ki so tedaj veljale za urejevanje gledališkega dela po vsej Avstriji. ${ }^{5}$

Ker je bilo jasno, da se gledališče ne more vzdrževati brez posebne dotacije in samo s pomočjo prostvoljnih prispevkov lastnikov lož in prijateljev gledališča, je gledališka uprava nekajkrat poskušala, da si zagotovi podporo iz javnega sklada, vendar pa ji to ni uspelo. ${ }^{6} \mathrm{~V}$ tedanjem času višji oblasti gledališče $\mathrm{v}$ provincialnem mestu, kot je bila Ljubljana, ni bilo nujno potrebna kulturna ustanova. Zato naj bi bilo navezano le na svoje lastne dohodke in na podporo občinstva.

Tako je guverner Schmidburg leta 1823 posredoval pri notranjem ministru in kanclerju grofu Saurau in predlagal letno podporo $\mathrm{v}$ višini 2000 fl.: $1500 \mathrm{fl}$. iz mestne blagajne in $500 \mathrm{fl}$. iz provincialnega fonda. ${ }^{7}$ Vendar je dobil negativen odgovor. $\mathrm{Na}$ prispevek iz provincialnega fonda sploh ni bilo računati, medtem ko bi bil prispevek iz mestne blagajne možen šele, ko bi se definitivno uredile ekonomske razmere mesta Ljubljane.

Naslednje leto je gledališka uprava dne 2. avgusta jasno predočila kritično situacijo guberniju. V svoji vlogi je opozorila, da sta možna le dva izhoda: ali odobritev pomoči v višini 2000 fl. ali sekvestracija dohodkov gledališkega fonda za odplačevanje davkov in dolgov, kar bi pomenilo, da bi se morala Ljubljana odpovedati gledališču. ${ }^{8} \mathrm{~S}$ priloženim izkazom je gledališka uprava guberniju dokazala, da so dosezali dohodki fonda letno le $600 \mathrm{fl}$., medtem ko je značal deficit $2013 \mathrm{fl} .25 \mathrm{kr}$., in nadalje poudarila, da ni poštenega gledališča $v$ monarhiji, ki ne bi uživalo s te ali one strani precej večje podpore, kot je vsota navedenega deficita. Žal pa tudi ta apel ni našel odmeva.

Ker gledališka uprava nikakor ni zmogla odplačati dolga, ki je znašal septembra leta 1824 že $7798 \mathrm{fl} .513 / 3 \mathrm{kr}$. — od tega $2552 \mathrm{fl} .37 \mathrm{kr}$. na račun zaostanka davkov in $5246 \mathrm{fl} .143 / 4 \mathrm{kr}$. na račun posojila iz provincialnega fonda - je gubernij dne 18. septembra 1824 odredil sekvestracijo gledališkega fonda, ki je stopila v veljavo dne 9. maja $1825 .{ }^{9}$ To pa je pomenilo, da je bilo ljubljansko gledališče docela odrezano še od dotedanjih skromnih dohodkov in da je podpora impresarijem bila $\mathrm{v}$ bodoče odvisna izključno od nestalnih prostovoljnih prispevkov lastnikov lož in prijateljev gledališča ter večinoma pičlih dohodkov gledaliških in redutnih plesov.

Navzlic temu pa je gledališka uprava tudi spomladi leta 1826 poskušala preskrbeti Ljubljančanom za naslednjo zimo gledališke predstave. Razpisala je natečaj, ${ }_{,}^{10}$ v katerem je seveda mogla bodočemu podjetniku zagotoviti le običajne skromne ugodnosti brez sleherne podpore $\mathrm{v}$ gotovini. Glede na to je tudi razumljivo, da ni mogla postavljati izrecnih zahtev po

5 Prim. Cretko D., ib. 211.

6 Prim. DAS-Gl a, Fasc. 75, 1823, št. 17.

7 Prim. DAS-Gl a, Fasc. 75, 1823, št. 30, 427.

8 Prim. DAS-Gl a, Fasc. 78, 1824, št. 9.

9 Prim. DAS.Gl a, Fasc. 78, 1825, št. 2, 17, 19; 1826, št. 22.

10 Prim. DAS-Gl a, Fasc. 78, 12. IV. 1826. 
operi, kar se odraža v sami stilizaciji razpisa, ki od podjetnika zahteva le angažiranje igralske družbe, katera bi bila sposobna izvajati poleg dramskega repertoarja kvečjemu še igrokaze s petjem.

Navzlic odrekanju sleherne denarne podpore pa je bilo zanimanje za ljubljansko gledališče tokrat dovolj živahno in tako so poslali prošnje, opremljene z vsemi potrebnimi listinami, trije konkurenti: Carl Waidinger, režiser in igralec v Innsbrucku, Carl Vio, gledališki podjetnik v Hartbergu na Štajerskem, in Sigmund van Binst, gledališki podjetnik iz Ulma. ${ }^{11}$

V Waidingerja uprava ni imela zaupanja, ker je že pred nekaj leti v Ljubljani s svojo družbo znatno prekoračil dane materialne možnosti in zapustil dolgove, medtem ko se ji je zdela družba Carla Via, ki je nastopala le po manjših mestih Štajerske, dvomljive kvalitete. Tako je prišel $\mathrm{v}$ poštev le van Binst, ki je imel odlična priporočila. Toda gledališka uprava, ki je bila zaradi uvedene sekvestracije fonda brez denarnih sredstev, ni hotela tvegati, da podeli entreprizo temu sicer sposobnemu impresariju, ki bi se moral s svojo družbo odpraviti na dolgo pot $\mathrm{v}$ kraje, kjer vlada popolna negotovost. Zato je $\mathrm{v}$ svoji vlogi deželnemu prezidiju predlagala, da se najem gledališča ustavi za nedoločen čas, dokler ne pridejo kako do denarja. Deželni prezidij je ta predlog dne 4. julija 1826 odobril, o čemer so tudi obvestili prosilce. ${ }^{2}$

Potem, ko gledališka uprava zaradi pomanjkanja denarnih sredstev ni tvegala angažirati čez zimo primerne družbe, je najprej skušala vsaj delno izpolniti to občutno vrzel $\mathrm{v}$ kulturnem življenju mesta $\mathrm{z}$ angažiranjem družbe operistov italijanskega impresarija Trevisana iz Udin, katere nastop z osemnajst do štiriindvajset predstavami so predvidevali $\mathrm{v}$ zadnjih dveh mesecih leta 1826 . Ker ni mogla plačati regala, je izdala prijateljem gledališča poziv za prostovoljne prispevke. ${ }^{13}$ Kakšen rezultat je ta akcija dosegla, iz aktov ne izvemo. Gotovo je le, da Italijanov tisto leto iz tega ali drugačnega vzroka $\mathrm{v}$ Ljubljano ni bilo.

Da pa Ljubljančani le ne bi ostali čisto brez gledališča, je guverner baron Schmidburg vzpodbudil kapelnika in skladatelja Gašparja Maška, ki je bil po rodu iz Češke in je že od leta 1820 deloval $v$ Ljubljani, ${ }^{14}$ da je zbral družbo diletantov, ki je uprizarjala dramske in operne predstave. Pevce in orkester tega ansambla so sestavljali člani Filharmonične družbe. Opero je vodil Mašek sam, medtem ko je vodstvo drame prevzela njegova žena Amalija, ki je bila pri nas že vrsto let znana kot izvrstna operna pevka. ${ }^{15}$ Keesbacher omenja, ${ }^{16}$ da so se vrstili vso sezono vsak teden izmenjaje po en koncert, ena dramska in ena operna predstava.

11 Prim. DAS-Gl a, Fasc. 78, 1826, št. 8-11, 13-15.

12 Prim. DAS-Gl a, Fasc. 78, 1826, št. 15, 16.

13 Prim. DAS-Gl a, Fasc. 78, 1826, št. 18, 20.

14 Prim. C-ZS (Comedien-Zattel Sammlung v Narodnem muzeju v Ljubljani) za 1820/21; D. Cvetko, ib., str. 170.

15 Prim. Cuetko D., ib., str. 195-200; Cuetko D., Odmevi glasbene klasike na Slovenskem, Ljubljana 1955, str. 96-97.

${ }_{16}$ Keesbacher F., Die Philharmosniche Gesellschaft in Laibach seit dem Jahre ihrer Gründung 1702 bis zu ihrer letzten Umgestaltung, Laibach 1862, str. 77. 
Sprva so bile gledališke predstave enako kot koncerti kar $\mathrm{v}$ redutni dvorani, pozneje pa $\mathrm{v}$ Stanovskem gledališču.

Vsekakor je to edinstven primer $\mathrm{v}$ zgodovini ljubljanskega gledališča, da so diletanti, ki so sicer le tu in tam uprizorili kako dramsko delo, oskrbeli s svojimi predstavami celo zimsko sezono in odpeli kar več oper. ${ }^{17}$ Keesbacher tudi navaja, da so diletanti izvedli naslednja glasbena dela: Boieldieujevi »Le Nouveau Seigneur de Village ( in »Le Dame Blanche(, »Deux Mots« N.Dalayraca, )Le Petit Matelot« P. Gaveauxa, Weiglovo »Die Schweizerfamilie«, »Joconde爪 $N$. Isouarda in Webrovo )Der Freischütz(.

Žal Keesbacher ne citira nikakršnega vira. Točno preverjanje njegovih podatkov pa ni mogoče, ker so viri, ki so na voljo, pomanjkljivi. Repertoarja za to sezono $v$ )Comedien-Zettel Sammlung ( $v$ Narodnem muzeju sploh ni, v mapi )Gledališki tiski« v Državnem arhivu Slovenije pa so ohranjeni za čas od 21. XI. 1826 do 28. III. 1827 le posamezni lepaki diletantskih predstav, in to za operi »Der Freischütz( (13.I. 1827) in )Jocondec (11. II. 1827) ter še za več dramskih iger. Iz lepakov, ki najavljajo dramske igre, razvidimo, da so diletanti $\mathrm{v}$ odmorih med dejanji tudi peli operne arije in ansamble, tako npr. arijo $\mathrm{z}$ zborom iz )Otella«, arijo iz oper »Die Zauberflöte« in »Der Freischütz«, duet iz )Sargina(, )Tancredac in »La gazza ladra(c ter kvartet iz Rossinijeve »Armide(, kar kaže, da so se povsem ravnali po praksi, ki je bila tedaj $\mathrm{v}$ navadi $\mathrm{v}$ poklicnem gledališču.

Enako kot ohranjeni lepaki pa nam ne dajo točne slike o sporedu diletantskih predstav kratke notice v »Laibacher Zeitung (, ki zajemajo čas od začetka decembra 1826 do začetka aprila 1827, a omenjajo še opere »Die Schweizerfamilie( (7. XII), »Der Freischütz« (7. I. in 24. II) in $) J o c o n d e\left(c\left(11\right.\right.$. II. in 19. III.).$^{18}$

Sicer je sploh vprašanje, če so vsa dela, ki jih omenja Keesbacher, diletanti tudi res izvedli. Glede Boieldieujeve »Le Dame Blanche« se zbuja dvom, ker nepodpisani recenzent, ki obširno poroča o predstavi te opere, ki je bila dne 12. XII. 1829, uvodoma v svojem precej obsežnem poroěilu poudarja, da je to prva predstava na ljubljanskem odru. ${ }^{19}$ Morda pa so diletanti uprizorili »Le Dame Blanche (e v redutni dvorani. Tako zaradi pomanjkanja virov za zdaj ni mogoče dokončno rešiti vprašanja datuma ljubljanske premiere te opere.

Spored, ki so se ga lotili naštudirati diletanti, je bil kvaliteten in za raven, ki jo moremo od njih pričakovati, zelo zahteven. $\mathrm{V}$ stilnem pogledu kaže $\mathrm{v}$ celoti iste značilnosti kot repertoarji poklicnih nemških družb, ki so $\mathrm{v}$ tistem času pri nas nastopale, tj. dominacijo opere romanskih avtorjev in ob prevladujoči klasiki že postopno uveljavljanje nove stilne smeri romantike. Od oper, ki jih navaja $\mathrm{v}$ zvezi $\mathrm{z}$ diletantskimi predstavami Keesbacher, sta bili Boieldieujeva »Le Dame Blanche« in Isouardova »Joconde« za Ljubljano pomembni noviteti.

17 Kasneje je izjema le še Bellinijeva »La Sonnambula« v izvedbi članov Filharmonične družbe 1. 1850; prim. LZg 1850, št. 13, 25, 18, 31.

18 Prim. LZg 1826 št. 97, 1827 št. 12, 14 in 21 ; IB 1827, št. 10.

19 IB 1829, št. 51. 
Opera »Joconde« spada med poslednja in najvrednejša dela skladatelja N. Isouarda. ${ }^{20}$ Clément, Larousse in Bitter jo soglasno ocenjujejo kot enega najbolj dovršenih primerov opére comique. ${ }^{21}$ To je delo, ki ga lahko postavimo ob stran operama, kot sta Boieldieujeva »Le Dame Blanche( ali Auberov »Fra Diavolo(c. Njegove odlike so lahkota, milina, živahnost ter duhovita in plemenita melodika. Skoro vse točke pokažejo skladatelja v najboljši luči. Posebna mojstrovina pa je kvartet v drugem dejanju, ki ga odlikuje obilje melodičnega čara, nenavadno fino tretiranje melodije in živo karakteriziranje oseb in situacij.

Opero »Joconde ou Les Coureurs d'Aventures«, za katero je napisal tekst C. G. Etienne, so prvič izvedli v Parizu leta 1814, naslednje leto že na Dunaju, v Budimpešti, Warszawi in Petrogradu. Nato so sledile uprizoritve kot npr. leta 1816 v Pragi, Münchenu, Berlinu in Madridu ter leta 1817 v Moskvi. Opero »Joconde (zizajajo tudi v zadnjem času. Tako so jo peli leta $1918 \mathrm{v}$ Parizu in leta $1931 \mathrm{v}$ Beauvaisu. ${ }^{22}$

»Le Dame Blanche๔ je bila v naslednjih desetletjih pri ljubljanski publiki najbolj priljubljena francoska opera. ${ }^{23}$ Ta opera je po krstni predstavi, ki je bila leta 1825 v Parizu, z nenavadno naglico osvojila evropska gledališča, tako da so jo že naslednje leto peli v Londonu, na Dunaju, v Berlinu, Bratislavi in Budimpešti. O njeni široki popularnosti govori tudi to, da se je pojavila kar $\mathrm{v}$ šestih nemških prevodih..$^{24}$

"Le Dame Blanche« je vrh Boieldieujeve ustvarjalnosti in eden najvrednejših primerov francoske opére comique. Libretist E. Scribe se je pri pisanju libreta naslanjal na nekatere dogodke romanov »The Monastery“ in »Guy Mannering( angleškega pripovednika W. Scotta in znal učinkovito povezati motive, kot so dozdevno izgubljeni junak, grad, v katerem straši, skriti zaklad in podobno. Značilno je pri tem tipično romantično mešanje prizorov iz stvarnosti in fantastike. Če izvzamemo sceno dražbe, operi docela manjka komični element, tako da je njen naziv komična opera upravičen le glede na njeno formo, ki vsebuje še govorjeni dialog.

)Le Dame Blanche« je eden prvih izrazitih primerov romantične opere. Nekateri jo celo imenujejo francoski pendant nemškega »Čarostrelca , , ker je imela v Franciji podobno vlogo kot ta Webrova opera v nemških deželah. Podobno kot izhaja Webrova glasba iz duha nemške ljudske pesmi, izhaja Boieldieujeva iz francoskega chansona. Razen tega pa je Boieldieu uporabil še škotske napeve, ki jih je učinkovito vpletal v svojo opero.

20 Prim. MGG V1, str. 1458, M. Briquet, članek N. Isouard.

21 Prim. Clément F.-Larousse P., Dictionnaire des Opéras, Paris 1904, geslo "Joconde«; Bitter C. H., Vergessene Opern, Gesammelte Schriften von C. H. Bitter, Berlin 1887, str. 106-107. str. 317.

${ }^{22}$ Prim. Loewenberg A., Annals of Opera 1597-1940, Cambridge 1943,

23 Prim. C-ZS od 1829-1837 in Blaznikovo Delovno knjigo za naslednja leta $\mathbf{v}$ Narodni in Univerzitetni knjižnici.

24 Prim. Loewenberg A., ib., str. 350-351. 
Boieldieu se sicer tudi tu ne pokaže kot skladatelj posebne izrazne globine. Toda navzlic temu odlikujejo njegovo glasbo kvalitete, ki opravičujejo dejstvo, da se je ta opera obdržala na repertoarju vse do današnjih dni. Dokaj obsežno delo $\mathrm{v}$ treh dejanjih ne deluje dolgovezno in nas nikjer ne dolgočasi. Skladateljeva invencija nikoli ne popusti. Sicer včasih nekoliko pusta Boieldieujeva melodika je zdaj pridobila pri toplini in prožnosti. Orkestracija je izpeljana s sigurno roko in je barvita. Poleg učinkovitih arij vsebuje opera tudi izvrstne ansamble, ki predstavljajo najmočnejšo umetniško vrednost partiture. ${ }^{25}$

Sicer pa so diletanti uprizorili le opere, ki so bile $\mathrm{v}$ Ljubljani že dobro znane. Med temi je poleg genialne in splošno znane Webrove mojstrovine »Der Freischütz ${ }^{26}{ }^{6}$ umetniško najbolj pomembna Boieldieujeva enodejanka »Le Nouveau Seigneur de Village $\left({ }^{27}\right.$ ki so jo v Parizu peli vse do leta 1898 in potem obnovili še leta $1934 . .^{28} \mathrm{Na}$ libretu, katerega dialog je fin, lahek in uglajen, šale duhovite in z mero okusa, se je skladatelju posrečilo zgraditi muzikalno resnično bogato partituro. ${ }^{29}$

Ostalo opere glasbenega sporeda diletantskih predstav »Deux mots ou Une nuit dans la forêt(c, )Le Petit Matelot( in »Die Schweizerfamilie(c so bile $\mathrm{v}$ tistem času sicer zelo priljubljene, vendar se $\mathrm{v}$ današnji čas niso ohranile. Lirsko opero »Die Schweizerfamilie ${ }^{30}$ nekoč renomiranega dunajskega skladatelja Josefa Weigla, so izvajali na vseh nemških odrih, razen tega pa tudi $\mathrm{v}$ drugih deželah. ${ }^{31}$ Weiglova glasba se izvrstno prilega značaju teksta, $v$ katerem se spajata vedri in sentimentalno obarvani resni element $\mathrm{v}$ enovito idilo. Ta glasba je prijetna, vsebuje ljubke in naivne melodije in nekaj efektnih ansamblov. Prav glede gradnje le-teh pa je Weigl pokazal več znanja kot njegova dunajska sodobnika Schenk in Müller. ${ }^{32}$ Tudi nepretenciozna glasba enodejanke »Deux mots ou Une nuit dans la forêt ( $^{33}$ teče gladko in neprisiljeno, a je mestoma prav duhovita. N. Dalayrac, ki je verno sledil tradiciji Monsignyja in Grétryja, je vsekakor znal pogoditi lahkotni konverzacijski ton francoske komedije. Instrumentalna spremljava je izdelana skrbno. Skladatelj je pokazal smisel za kolorit, ki ga doseza $\mathrm{z}$ domiselnim izkoriščanjem pihal. ${ }^{34}$ Komična opera »Le Petit Matelot« skladatelja P. Gaveauxa ${ }^{34}$ a je uživala nekoč velik

25 Prim. Grout D. J., A Short History of Opera, New York 1956; Knepler G., Musikgeschichte des XIX. Jahrhunderts, I, Berlin 1961, str. 260-261; MGG (Musik in Geschichte und Gegenwart), II, str. 68.

${ }_{26}$ Ljubljanska premiera 1. 1825, gl. C.ZS 1824/25.

27 Ljubljanska premiera 1. 1822, gl. C-ZS 1821/22.

28 Loewenberg A., ib., str. 316.

${ }^{29}$ Prim. Favre G., Boieldieu, II, Paris 1945, str. 67-68; Klob K. M., Die Oper von Gluck bis Wagner, Ulm 1913, str. 242-244.

30 Ljubljanska premiera 1. 1815, gl. C-ZS 1814/15.

31 Loewenberg A., ib., str. 112.

32 Prim. Bollert W., Josef Weigl und das deutsche Singspiel v Aufsätze zur Musikgeschichte 1938, str. 99, 100; Klob K. M., ib., str. 179-180; Wallaschek R., Das k. k. Hofoperntheater, Wien 1909, str. 51-52.

${ }^{33}$ Ljubljanska premiera 1822, gl. C-ZS 1821/22.

34 Prim. partituro 25054 v Österreichische National Bibliothek.

34a Ljubljanska premiera 1. 1815, gl. C-ZS 1814/15. 
sloves predvsem zaradi glasbenega slikanja nevihte, ki deluje danes precej otročje in banalno, a je bila publiki tistih časov zelo všeč. ${ }^{34} b$

Že samo obravnavani spored diletantskih predstav za sezono 1826/27 izpričuje torej nedvomno veliko vnemo in prizadevnost ter resno umetniško voljo njihovega glasbenega vodje, dirigenta Maška. Škoda, da kratke časopisne notice ne pristavljajo niti besedice, ki bi vsaj malo nakazovala kvaliteto in uspeh predstav. Keesbacher sicer pravi, da so bili diletanti polni najboljše vneme, tako da je bila dosežena zaokroženost izvedb, kot da so člani tega ansambla že leta navajeni drug drugega. ${ }^{35}$ Žal pa svoje trditve ne podpre $\mathrm{z}$ virom. Vendar je videti, da ta le ni neosnovana, saj jo potrjuje tudi izjava same Maškove $\mathrm{v}$ prošnji za podelitev ljubljanskega gledališča za leto 1834/35, v kateri se sklicuje na predstave diletantov, )ki jih je vodila s svojim soprogom zelo uspešno in $\mathrm{v}$ splošno odobravanje. ${ }^{36}$

Ne glede na to je jasno. da diletanti niso mogli doseči tistega, kar so zmožni dati poklicni pevei in igralci. Ker torej dilatantsko gledališče ni moglo biti enakovredno nadomestilo za profesionalno in ker od diletantov tudi ni pričakovati, da bi se dlje časa v širšem obsegu posvečali gledališkemu delu, je gledališka uprava navzlic sekvestraciji fonda poskušala obnoviti profesionalno gledališce in objavila $\mathrm{v}$ časopisju razpis za sezono $1827 / 28 .^{37}$ Zaradi pomanjkanja slehernih lastnih denarnih sredstev pa je bila pripravljena, da se zadovolji tudi s kakšno povprečno gledališko družbo brez opere. In tako se je moralo ljubljansko občinstvo $\mathrm{v}$ naslednjih dveh sezonah, ko je bilo umetniško vodstvo gledališča v rokah impresarija Carla Waidingerja, ${ }^{38}$ spet odreči uživanju operne umetnosti.

\section{SUMMARY}

Since the economic situation of the Ljubljana Theatre after the reorganisation of its administration in 1819 instead of improving had been continually deteriorating, the Theatre Board tried to obtain assistance from public funds. Unfortunately its request was turned down and so the theatre had to continue to depend on its own income and the support of the public. Owing to a large increase in debts and the non-payment of taxes, the government ordered the sequestration of the theatre funds. This came into effect in 1825. The theatre was being completely cut off from its modest income, the subsidy for the impresarios depended exclusively on the irregular voluntary subscriptions of the box-owners and the friends of the theatre and the generally meagre income from theatre balls and theatre-directed town balls. As a consequence of this the Board in its communication to the Provincial Praesidium suggested that they might give up the lease for an indefinite period until the money should be available. The suggestion was accepted by the Praesidum.

34b Prim. Clément F.-Larouse P., ib., geslo »Le Petit Matelot«.

35 Prim. Keesbacher F.,ib., str. 77.

36 DAS-Gl a, Fasc. 78, št. 158, 17. V. 1833.

37 Prim. DAS-Gl a, Fasc. 78, 8. III. 1827, št. 2.

38 Prim. C-ZS 1827-1829. 
That the public of Ljubljana should not lack theatre performances throughout the season 1826-27 the Governer Schmidburg encouraged the composer and conductor Gašpar Mašek to assemble a company of amateurs to stage dramatic and operatic works. Their repertoire included the following operas: "Le Nouveau Seigneur de Village« and "Le Dame Blanche« by Boieldieu, »Deux Mots« by N.Dalayrac, »Le Petit Matelot« by S. Gaveaux, »Die Schweizerfamilie« by Weigl, "Joconde« by N. Isouard and Weber's »Der Freischütz«. At any rate it is a unique case in the history of the Ljubljana Theatre that the amateurs who otherwise only performed a few dramatic plays provided drama for a whole season and staged even several operas. The repertoire mentioned was exacting and of high quality and testifies to their ardour and their strong determination. According to the report of Keesbacher the opera performances were also of an adequate artistic standard.

Nevertheless it is clear that the amateurs were unable to attain the same level as professional actors and singers. Consequently the Theatre Board tried in spite of the sequestration of the funds to re-open the professional theatre and, to this end, it announced the re-letting of the theatre for the season 1827-28. 